\title{
Sustained Improvement of Arterial Blood Oxygenation, Maximum Oxygen Consumption and Maximum Walking Distance after Treadmill Training in Healthy EIderly Subjects?
}

\author{
Ashraf Adel Bichay ${ }^{1}$, Mohamed Farouk Allam ${ }^{2, *}$, Maria S. Poblador Fernández ${ }^{1}$ and \\ José Luis Lancho Alonso ${ }^{1}$ \\ ${ }^{1}$ Morphological Sciences Department. Faculty of Medicine, University of Cordoba, Cordoba, Spain
${ }^{2}$ South Cordoba Health District. Lucena, Cordoba, Spain
}

\begin{abstract}
Background. Physical activity is known to play an important role in improving the cardio-pulmonary function and arterial blood oxygenation $(\mathrm{SaO} 2)$ in elderly subjects. Objective. To evaluate the therapeutic efficacy of treadmill training on $\mathrm{SaO} 2$, maximum oxygen consumption $\left(\mathrm{VO}_{2}\right.$ max $)$ and maximum walking distance in elderly healthy subjects. Design. Intervention study Setting. El Salam General Hospitals, Cairo (Egypt). Participants. Our study included 41 subjects. All participants appeared healthy, without chronic diseases and passed the Cardiopulmonary Exercise Test. Intervention. Participants were incorporated in a treadmill-training program of moderate intensity to attain a fraction of $60 \%$ to $70 \%$ of the maximum heart rate. After 12 weeks of controlled physical activity, the program was made voluntarily for 36 weeks. Measurements. $\mathrm{SaO} 2, \mathrm{VO}_{2}$ max and maximum walking distance were measured for each individual one-week before and 12 weeks after training and at the $30^{\text {th }}$ and the $48^{\text {th }}$ week of the program. Results. Our study included 20 men and 21 women, with mean age of $65.1+2.7$ years (Range 60-69). An increase in the mean values of $\mathrm{SaO}_{2}, \mathrm{VO}_{2}$ max and maximum walking distance after 12 weeks of controlled exercise and also at the $30^{\text {th }}$ week and the $48^{\text {th }}$ week of the program $(\mathrm{P}<0.05)$. There has been a decrease in the mean values of $\mathrm{VO}_{2}$ max, $\mathrm{SaO} 2$ and maximum walking distance after the $30^{\text {th }}$ and $48^{\text {th }}$ week in comparison with the values after the first 12 weeks. Conclusion. Controlled treadmill training for 12 weeks improved $\mathrm{SaO} 2, \mathrm{VO}_{2}$ max and maximum walking distance of the participants. The mean values of the participants decreased after the $30^{\text {th }}$ and $48^{\text {th }}$ week due to lack of adherence to the unsupervised program.
\end{abstract}

Keywords: Treadmill, exercise, $\mathrm{SaO} 2, \mathrm{VO} 2$ max, walking distance.

\section{INTRODUCTION}

Aging is a process that leads to death and is characterized by universal progressive alterations and irreversible damaging. Aging is not a disease; we can treat age-related phenomena, but not aging itself [1].

The age-related decline in aerobic capacity is associated with all-cause cardiovascular mortality and can lead to functional decline and dependency [2]. The decline in lung function is not noticed until the person reaches 60,70 or even 80 years old. The exposure to environmental toxins along the whole life of a person could contribute to a faster decline in lung function in the elderly. This decline may adversely affect the ability of senior citizens to exercise [3]. Cardiopulmonary exercise test (CPET) and walking tests have proven to be useful in the individual prescription of pulmonary rehabilitation and oxygen supplementation [4].

Aging is also associated with a decrease in postural control, gait speed, stride length and the distance walked during the synchronized walking test and there is also an increase in the variability of the gait. However there are many tools

*Address correspondence to this author at the Responsible for Epidemiology and Research, South Cordoba Health District. Ctra. Cordoba - Malaga, Km 69, 14900 Lucena - Cordoba, Spain; Tel: 957596364;

Fax: 957596352; Email: fm2faahm@uco.es available to help health professionals in the identification and quantification of gait disorders and functional capacities [5].

The objective of our study is to evaluate the therapeutic efficacy of treadmill exercises on the arterial blood oxygenation $(\mathrm{SaO} 2)$, maximum oxygen consumption $\left(\mathrm{VO}_{2} \max \right)$ and maximum walking distance in elderly healthy subjects, together with the effectiveness of short-term monitored training programs and long-term unsupervised program.

\section{SUBJECTS AND METHODS}

Elderly subjects were invited to participate in this study. Participants were randomly selected from the Dermatology, Ophthalmology and ENT Outpatient Clinics of El Salam General Hospital in Cairo, Egypt.

El Salam General Hospitals include two main hospitals: El Salam General Hospital and El Salam Specialized Hospital. These hospitals are located in the eastern part of Cairo and have 1000 beds capacity. It has different medical and surgical specialties serving more than one million people of adults and children in the east of Cairo and the nearby villages.

Inclusion criteria to participate in the study were as follows; age varying between 60 and 70 years, non-smokers or 
former smokers for more than 5 years and good general health.

Exclusion criteria were neuromuscular, orthopedic, neurological or cardio-pulmonary diseases. Also we excluded patients with any chronic deficit that would prevent exercise. Chest X-ray and ECG were performed to exclude any underlying pathology before realizing the exercise tolerance test, which was done according to the protocol of Naughton [6]. This protocol, realized using a treadmill, it begins with 2 minutes of warming. The speed is set at one mile per hour and the slope is set at 0 degree. After warming up the speed is set at 2 miles per hour and doesn't change for the rest of the test. The test consists of six minutes with 2 minutes intervals. At the first interval the slope starts by 0 degree inclination and it increases by 3.5 percent every 2 minutes.

The study was approved by the ethics committee of El Salam General Hospital in Cairo on the15th of January of 2007.

Forty-one persons, 20 men and 21 women accepted to participate in the study and were followed up over 48 weeks. After performing a complete medical history, participants were instructed of the procedure and signed an informed consent.

Necessary anthropometric measures were recorded as height and weight to calculate Body Mass Index (BMI) and were introduced into the software along with the demographic data of the subjects (name, age and sex). In the same occasion, instructions were given to the subjects to avoid food intake 2 hours before the test, the measures of hygiene and comfort in clothing as well as in footwear and to avoid any unusual physical efforts at least 12 hours before the test.

\section{Equipment and Instruments Used for the Test and the Program}

- A Cardiopulmonary Exercise Test unit (CPET) Zan 800. It is a gas analyzer of $(\mathrm{O} 2$ and $\mathrm{CO} 2)$ for the measurement of the maximum oxygen consumption (VO2max).

- Pulse Oximeter CMS 50DL Finger Pulse Oximeter to measure the oxygen saturation $\left(\mathrm{SaO}_{2}\right)$.

- 12 Channels Electrocardiogram Biocare (ECG-8080).

- Mercury sphygmomanometer and stethoscope Littman Classic II SE.

- A treadmill DKN Run Tech 2.5 with adjustable speed, inclination and timer, and a large LCD screen with 23 training programs and 3 users profiles. The screen displays simultaneously walking time and distance, speed, inclination, burned calories and heart rate.

- Height and weight scale IPR-scale08 model, for the measurement of height, weight and can calculate your BMI automatically.

- Pulsometer (HR) p610 Accurex Plus for monitoring of heart rate. Although ECGs of all participants were normal, heart rate were monitored to assure not exceeding 120 at any moment of the exercise.

\section{Mode of Exercises}

Walking on treadmill with fixed $0 \%$ grade of inclination. The treadmill should have front and/or side rails to aid in subject stability.

The training program consists of 3 phases, which are the followings:

- Warming up phase of 5 minutes on the treadmill.

- Active phase in which the speed of the treadmill is increased to achieve at least $60 \%$ and not more than $70 \%$ of the maximum heart rate (HR max) according to the protocol of Fletcher and collaborators 2001[6]. The treadmill inclination is fixed at $0 \%$ grade during the whole program, so the intensity of the exercise could be increased or decreased only by changing the speed of the treadmill. The active phase of exercise is 20 minutes for the first 3 weeks, 30 minutes for the next two weeks, 40 minutes for the followings two weeks and finally for 50 minutes till the end of the program.

- Cooling down phase for a period of 5 minutes, which is achieved by reducing the speed gradually till reaching zero and until the heart rate, returned almost to the resting level.

The $\mathrm{SaO} 2, \mathrm{VO} 2 \mathrm{max}$ and maximum walking distance were measured for each individual one-week before and 12 weeks after training and at $30^{\text {th }}$ and $48^{\text {th }}$ week of the training program. They were measured by the following techniques:

\section{Measurement of Oxygen Saturation $\left(\mathrm{SaO}_{2}\right)$}

Oxygen saturation was measured two months prior to training; pulse oximeter was used to measure Oxygen saturation in the right index of each individual. Each individual had to rest for two minutes before the beginning of the measurement. After placing the sensor on the finger, we waited until a reading was displayed on the oximeter, than we waited for another 10-15 seconds to verify a steady signal, this is followed by recording $\mathrm{SaO} 2$ and pulse every 10 seconds. Six observations were recorded and their average was used as the individual's $\mathrm{SaO}_{2}$ as in previous studies [7].

\section{Measurement of Maximum Oxygen Consumption (VO2max)}

A gas analyzer of $\mathrm{O} 2$ and $\mathrm{CO} 2$ was used for the measurement of maximum oxygen consumption. Before conducting the test, the humidity collector was cleaned, the connected tube was checked, the triple $\mathrm{V}$ - valve sensor disinfected and the gas analyzer was calibrated. The heart rate and blood pressure were detected in relaxed sitting position for each subject of the group. The mask was fixed with straps and then the triple tube $\mathrm{V}$ was connected to the mask. Initially, metabolic parameters such as oxygen consumption, carbon dioxide production and heart rate at rest were measured every three minutes.

\section{Measurement of the Maximal Walking Distance}

Each subject performed a progressive graded treadmill test at a speed of 2 miles per hour (MPH), starting at $0 \%$ grade of inclination and the grade was increased by $2 \%$ 
every 2 minutes. The test is terminated when the maximal effort is reached or when the subject experienced dypsnea or leg pain. The primary outcomes determined by the treadmill test were the maximal walked distance [8].

\section{Schedule of the Training Program}

The participants were incorporated in an training program of moderate intensity (walking on the treadmill) 3 times weekly for 48 weeks, the first 12 weeks were supervised and the resting 36 weeks of the program were unsupervised. After the $30^{\text {th }}$ week and the $48^{\text {th }}$ week an assessment was done and the participants were categorized into 3 sub groups according to their compliance with the training program:

Group 1: Subjects who have complied with the whole program.

Group 2: Subjects who have partially completed the program (at least once a week).

Group 3: Subjects who haven't done any physical activity (less than 4 times per month).

Unsupervised exercise implied walking on the treadmill programed for the study for at least 30 minutes in the Department of Physical Medicine and Rehabilitation of El Salam General Hospital of Cairo (Egypt).

\section{Statistical Methods}

First, the following descriptive analysis was done: frequency, percent, mean, standard deviation. Thereafter, comparisons were done using the student's t-test for continuous variables and Pearson's Chi square test for categorical variables. Level of significance was set at $P<0.05$. All data variables were encoded and computerized. Data entry and statistical analysis were performed using the Statistical Package for Social Science (SPSS) version 15.0 (SPSS Inc., Chicago, Illinois).

\section{RESULTS}

Our intervention study included 41 persons, 20 men representing $48.8 \%$ of the group and 21 women representing
$51.2 \%$ of the study group. Their ages ranged between 60 and 69 with an average of 65.1 years (SD 2.7). Their weights were from 78 to $86 \mathrm{~kg}$ with an average of $81.8 \mathrm{~kg}$ (SD 2.2). Their heights were 162 to 173 centimeters, with a mean value of 168.1 (SD 3) and their body mass index (BMI) ranged from 26.7 to 31.6 with a mean of 29 (SD 1.1).

At the beginning of the program, men had higher mean values of VO2 max, maximum walking distance and a lower $\mathrm{SaO} 2$ than women with significant statistical differences $(\mathrm{P}<0.05)$ (Table 1).

All participants achieved the controlled program (the first 12 weeks).

Between $12^{\text {th }}$ and $30^{\text {th }}$ week of the unsupervised program, the results were as follows: $34 \%$ of the subjects had fully complied with the program and $25 \%$ have partially completed it and $41.5 \%$ have not done any exercise (Table 2).

Between the $30^{\text {th }}$ and $48^{\text {th }}$ week of the unsupervised program, the results were as follows: $34 \%$ of the subjects had fully complied with the program and $29 \%$ have partially completed it and 37\% have not done any exercise (Table 3 ).

About $45 \%$ of the participants $(90 \%$ of women in comparison with $30 \%$ of men) adhered to the long-term unsupervised program,

An increase in the mean values of $\mathrm{VO} 2$ max, $\mathrm{SaO} 2$ and maximum walking distance after 12 weeks of controlled exercise and also at the $30^{\text {th }}$ week and the $48^{\text {th }}$ week of the program, with significant statistical differences $(\mathrm{P}<0.05)$ (Table 1).

There has been a decrease in the mean values of VO2 max, $\mathrm{SaO} 2$ and maximum walking distance after the $30^{\text {th }}$ and $48^{\text {th }}$ week (unsupervised program) in comparison with the values after the first 12 weeks (controlled program) (Table 1).

After the 12 weeks of the controlled training program, men maintained the higher mean values of $\mathrm{VO} 2$ max and maximum walking distance than women with significant statistical differences $(\mathrm{P}<0.05)$, on the other hand women had a higher statistic significant differences in $\mathrm{SaO} 2$ $(\mathrm{P}<0.05)$.

Table 1. Comparative Study and Monitoring of Maximum Oxygen Consumption (VO2max), Maximum Walking Distance (WDmax) and Arterial Oxygen Saturation (SaO2) of the Participants

\begin{tabular}{|c|c|c|c|}
\hline Variables & $\begin{array}{c}\text { VO2max } \\
\text { Mean } \pm \text { SD (Range) }\end{array}$ & $\begin{array}{c}\text { WDmax } \\
\text { Mean } \pm \text { SD (Range) }\end{array}$ & $\begin{array}{c}\mathrm{SaO2} \\
\text { Mean } \pm \text { SD (Range) }\end{array}$ \\
\hline Pre-training & $\begin{array}{c}1.75 \pm 0.13 \\
(1.60-1.93)\end{array}$ & $\begin{array}{c}688.54 \pm 33.46 \\
(623-745)\end{array}$ & $\begin{array}{c}96.90 \pm 0.54 \\
(96-98)\end{array}$ \\
\hline 12 Weeks & $\begin{array}{l}1.95 \pm 0.90 * \\
(1.79-2.05)\end{array}$ & $\begin{array}{c}861.44 \pm 57.18 * \\
\quad(766-952)\end{array}$ & $\begin{array}{c}98.37 \pm 0.54 * \\
(97-100)\end{array}$ \\
\hline 48 Weeks & $\begin{array}{l}1.87 \pm 0.12 * \\
(1.59-2.18)\end{array}$ & $\begin{array}{c}783.71 \pm 75.25 * \\
(650-909)\end{array}$ & $\begin{array}{c}97.73 \pm 1.10 * \\
\quad(96-100)\end{array}$ \\
\hline
\end{tabular}

* $\mathrm{P}<0.05$ (Reference Pre-training) 
Table 2. Comparative Study and Monitoring of Participants' Compliance with the Training Program Between 12 and 30 Weeks According to Gender

\begin{tabular}{|c|c|c|c|}
\hline Physical exercise between 12-30 weeks & $\begin{array}{c}\text { Women } \\
\text { N (\%) }\end{array}$ & $\begin{array}{c}\text { Men } \\
\text { N (\%) }\end{array}$ & $10(50.0)$ \\
\hline N (\%)
\end{tabular}

Pearson Chi-square: 1.65 - P value: 0.44

Table 3. Comparative Study and Monitoring of Participants' Compliance with the Training Program Between 30 and 48 Weeks According to Gender

\begin{tabular}{|c|c|c|c|}
\hline Physical exercise in 48 weeks & $\begin{array}{l}\text { Women } \\
\text { N (\%) }\end{array}$ & $\begin{array}{c}\text { Men } \\
\text { N (\%) }\end{array}$ & $\begin{array}{l}\text { Total } \\
\text { N (\%) }\end{array}$ \\
\hline Haven't done any physical exercise & $2(9.52)$ & $13(65.0)$ & $15(36.6)$ \\
\hline Partially completed the training program & $7(33.33)$ & $5(25.0)$ & $12(29.3)$ \\
\hline Totally completed the training program & $12(57.14)$ & $2(10.0)$ & $14(34.1)$ \\
\hline
\end{tabular}

Pearson Chi-square: 15.53 - P value: 0.00

At the $30^{\text {th }}$ week, men had higher mean values of VO2max and maximum walking distance than women $(\mathrm{P}<0.05)$; meanwhile women had higher values of $\mathrm{SaO} 2$ than men $(\mathrm{P}<0.05)$.

At the $48^{\text {th }}$ week, women had higher mean values of $\mathrm{SaO} 2$ and maximum walking distance than men, with significant statistical differences for $\mathrm{SaO} 2$.

At the $30^{\text {th }}$ and $48^{\text {th }}$ weeks participants who complied with the unsupervised program didn't have more improvement in the values of $\mathrm{SaO} 2, \mathrm{VO} 2$ max and maximum walking distance in comparison with these values at $12^{\text {th }}$ week of the controlled program. Values were maintained at the $12^{\text {th }}$, $30^{\text {th }}$ and $48^{\text {th }}$ week of the program with no significant statistical differences (Table 4).

\section{DISCUSSION AND CONCLUSION}

Elderly subjects are commonly associated with cardiopulmonary and vascular problems; the physical activity plays an important role in improving the cardio-pulmonary function and arterial oxygen saturation [9]. As long as the elderly population continues to increase, it will be essential for primary healthcare physicians to insist that sedentary patients have to practice physical exercise regularly [10].

The objective of the current intervention study was to evaluate the therapeutic efficacy of treadmill exercises on $\mathrm{SaO} 2$, maximum oxygen consumption (VO2 max) and maximum walking distance in elderly healthy subjects.

Before reaching conclusions based on the present results, it is necessary to consider a number of potential objections to the methodology.
Limitations such as the small sample size could affect the validity of the results. Our study included only 41 elderly healthy subjects. It was to difficult to identify more subjects between 60 and 70 years old without any chronic disease and accept to participate in a follow up study for nearly 1 year. Another possible limitation was each participant's psychological status at the time of exercise and his or her compliance to the supervised program. Although these limitations could not be avoided, our findings strongly suggest that exercise training program on treadmill (short or long-term) is capable of improving VO2 max, $\mathrm{SaO} 2$ and maximum walking distance of elderly healthy subjects.

In our intervention study, controlled treadmill exercises for 12 weeks improved clearly $\mathrm{VO} 2$ max, $\mathrm{SaO} 2$ and maximum walking distance of the studied population.

It is well known that $\mathrm{SaO} 2$ tends to decline markedly in the fifth and sixth decade. Adult women usually maintain a higher $\mathrm{SaO} 2$ and began to exhibit differences at a later age than men [7].

A recent study showed that training exercise program for 3 months with the treadmill in an elderly population (mean age 69 years) improves oxygen saturation [11]. In contrary, another previous study with a group of 16 women, aged 8093 years, who participated in an exercise test 4-month intervention, there was no change in $\mathrm{SaO} 2$ [12].

The improvement in $\mathrm{SaO} 2$ could be attributed to the better ventilatory response to exercise in the elderly than in the young. This seems to offset the increased inefficiency of gas exchange in the senior age [13].

It was shown that up to one third of the decline in aerobic capacity (VO2 max) associated with aging could be reversed 
Table 4. Comparative Study and Monitoring of Maximum Oxygen Consumption (VO2max), Maximum Walking Distance (WDmax) and Arterial Oxygen Saturation (SaO2) of Participants who Completed the Unsupervised Training Program

\begin{tabular}{|c|c|c|c|}
\hline Variables & $\begin{array}{c}\text { VO2max } \\
\text { Mean } \pm \text { SD (Range) }\end{array}$ & $\begin{array}{c}\text { WDmax } \\
\text { Mean } \pm \text { SD (Range) }\end{array}$ & $\begin{array}{c}\text { SaO2 } \\
\text { Mean } \pm \text { SD (Range) }\end{array}$ \\
\hline \hline 12 Weeks* & $\begin{array}{c}1,92 \pm 0,07 \\
(1,82-2,05)\end{array}$ & $\begin{array}{c}847,47 \pm 48,89 \\
(772-936)\end{array}$ & $\begin{array}{c}9,59 \pm 0,51 \\
(97,60-99,50)\end{array}$ \\
\hline 30 Weeks & $\begin{array}{c}1,92 \pm 0,11 \\
(1,75-2,15)\end{array}$ & $\begin{array}{c}834,00 \pm 54,53 \\
(732-928)\end{array}$ \\
\hline 48 Weeks & $\begin{array}{c}1,92 \pm 0,11 \\
(1,72-2,18)\end{array}$ & $\begin{array}{c}842,26 \pm 40 \pm 0,54,66 \\
(736-909)\end{array}$ & $\begin{array}{c}98,53 \pm 0,78 \\
(96,80-99,60)\end{array}$ \\
\hline
\end{tabular}

* Reference

$\mathrm{P}$ value $<0.05$

by prolonged aerobic training [14]. The lower VO2max in women was attributed to smaller muscle mass, lower hemoglobin, blood volume and stroke volume than that of men [6]. Brisk walking, if practiced at moderate intensities (e.g. three to four miles/hour) can result in improved health and aerobic capacity [15]. It is estimated that every minute of normal gait increased per day increases VO2 max. by 0096 $(\mathrm{ml} / \mathrm{kg} / \mathrm{min})$ and is possibly associated with a faster gait [16]. Previous study showed that aerobic training programs increase VO2max from $6.6 \%$ to $30 \%$ in the elderly [2].

In healthy slightly active young men VO2max. was 12 METs (Metabolic Equivalents), whereas individuals performing aerobic training such as running (long distance running) can have a VO2max.ranging from 18 to 24 METs [6]. The older individuals increase their maximal oxygen consumption by a redistribution of cardiac output to the members exercised, resulting in a proportional increase in systemic oxygen AV (arteriovenous) difference without a change in peripheral oxygen extraction [17].

Ageing is associated with a decrease in postural control, gait speed, stride length and walking distance as well as an increase in variability of gait during a timed walk test [5]. Muscle strength declines by $1.5 \%$ per decade after age 50 and $30 \%$ per decade after age 70 . This is mainly due to sarcopenia (loss of muscle mass) and occurs more in women than in men [10]. Most of the variation in walking speed in older people is related to leg strength and increasing it has shown improvement in the resistance of walking and improving the power to climb stairs [18]. Previous intervention study showed that after training exercise program for 3 months with the treadmill in an elderly population (mean age 69 years), there was an improvement in distance walked [11]. Another intervention study conducted by Sullivan and collaborators (2007) on patient with chronic stroke reported similar results were observed. Task-specific training was conducted during a walk test on a treadmill with body weight, combining the walk on the treadmill with and without strengthening exercises of the lower extremity. All groups increased the speed and walking distance in both cases [19].

In our study best results were achieved during the first 12 weeks (short-term controlled program) and the subjects who complied with the whole program maintained the same values of the controlled program at the $30^{\text {th }}$ and $48^{\text {th }}$ week (un- supervised program) without any more gain over the last 36 weeks of the program. In concordance with our study, it was reported that patients ranging from zero to a little exercise, get the greatest health benefits, while the improvement is less noticeable when gradually increasing the level of physical activity [15].

In our intervention study we noticed that subjects whose compliance were monitored and received a feedback on their developments and progress were more adherents to the program than patients without supervision. There has been a decrease in the mean values of the whole group after the $30^{\text {th }}$ and $48^{\text {th }}$ week (unsupervised program) in comparison with these values during the first 12 weeks (controlled program), due to lack of adherence of the participants to the long-term unsupervised program. Women had better adherence to the long-term program and therefore gained more health benefit and had maintained these benefits for longer period of time. A previous similar study reported compliance decrease from $59 \%$ in the supervised program to $29 \%$ after 6 months of unsupervised exercise [20]. Physical therapists estimate that $64 \%$ of patients comply with exercise regimens in the short term, but only $23 \%$ of them meet the long-term exercise [21].

Previously it was reported that elderly who participate in moderate physical exercise intensity, between 20 and 30 minutes, most days of the week, have better shape than the elderly that are active or inactive throughout the day [22]. Fletcher and collaborators (2001) noted 25\% decrease in VO2max in healthy men after 3 weeks of being bedridden, and demonstrated that physical activity has an important influence on their vital capacity [6].

In conclusion, our findings were consistent, coherent and strongly indicate the external validity of the study. Although, these results pertain only to our population/hospital and could not be generalizable, the same methodology could be applied in different populations/hospitals. Our results call for further investigation of the effect of treadmill training in elderly; future study should preferably be performed on large prospective cohorts, to increase their internal validity.

\section{CONFLICT OF INTEREST}

The author(s) confirm that this article content has no conflicts of interest. 


\section{ACKNOWLEDGEMENT}

We extend our sincere thanks to the staff of the Department of Physical Medicine and Rehabilitation of El Salam General Hospital of Cairo (Egypt), Department of Morphological Sciences and Sports Medicine of Faculty of Medicine, University of Cordoba (Spain) and Department of Physical Education of the Universite Libre de Bruxelles (Belgium) for their willing co-operation in the study.

\section{"What is Already Known"}

Cardio-pulmonary exercise test and walking tests have proven to be useful in the individual prescription of pulmonary rehabilitation and oxygen supplementation.

\section{"What this Study Adds"}

Controlled treadmill exercises for 12 weeks improve arterial blood oxygenation, maximum oxygen consumption and maximum walking distance in healthy elderly subjects.

Mean values of arterial blood oxygenation, maximum oxygen consumption and maximum walking distance decrease after the $30^{\text {th }}$ and $48^{\text {th }}$ week in case of no adherence to the exercise program.

\section{REFERENCES}

[1] American Thoracic Society. Aging, the aging lung, and senile emphysema are different. Am J Respir Crit Care Med 2007; 175(2): 197-8.

[2] Kalapotharakos VI. Aerobic exercise in older adults: Effects on VO2 max and functional performance. Crit Rev Phys Rehab Med 2007; 19: 213-25.

[3] Camhi SL, Enright PL. How to assess pulmonary function in older adults. J Respir Dis 2000; 21(6): 395-400.

[4] Palange P, Ward SA, Carlsen K-H, et al. Recommendations on the use of exercise testing in clinical practice. Eur Respir J 2007; 29:185-209.

[5] Harris MH, Holden MK, Cahalin LP, Fitzpatrick D, Lowe S, Canavan PK. Gait in older adults: a review of the literature with an emphasis toward achieving favorable clinical outcomes, Part II. Clin Geriatr 2008; 16(8): 37-45.

[6] Fletcher GF, Balady GJ, Amsterdam EA, et al. Exercise standards for testing and training. Circulation 2001; 104: 1694-740.
[7] Beall CM. Oxygen saturation increases during childhood and decreases during adulthood among high altitude native Tibetians residing at 3,800-4,200m. High Alt Med Biol 2000; 1(1): 25-32.

[8] Gardner AW, Skinner JS, Cantwell BW, Smith LK. Progressive vs single-stage treadmill tests for evaluation of claudication. Med Sci Sports Exerc 1991; 23(4): 402-8.

[9] Lakatta EG. Age-associated cardiovascular changes in health: impact on cardiovascular disease in older persons. Heart Fail Review 2002; 7(1): 29-49.

[10] Nied RJ, Franklin B. Promoting and prescribing exercise for the elderly. Am Fam Physician 2002; 65(3): 419-26.

[11] Figoni SF, Kunkel CF, Scremin AM, et al. Effects of exercise training on calf tissue oxygenation in men with intermittent claudication. Phys Med Rehab 2009; 1(10): 932-40.

[12] Huang YJ, Chen MT, Fang CL, Lee WC, Yang SC, Kuo CH. A possible link between exercise-training adaptation and dehydroepiandrosterone sulfate- an oldest-old female study. Int J Med Sci 2006; 3(4):141-7.

[13] Brischetto MJ, Millman RP, Peterson DD, Silage DA, Pack AI Effect of aging on ventilatory response to exercises and $\mathrm{CO} 2 . \mathrm{J}$ Appl Physiol 1984; 56: 1143-50.

[14] Shephard RJ. Maximal oxygen intake and independence in old age. Br J Sports Med 2009; 43(5): 342-6.

[15] Pate RR, Pratt M, Blair SN, et al. Physical activity and public health: a recommendation from the centers for disease control and prevention and the American College of sports medicine. JAMA 1995; 273(5): 402-7.

[16] Wong CH, Wong SF, Pang WS, Azizah MY, Dass MJ. Habitual walking and its correlation to better physical function: implication for prevention of physical disability in older persons. J Gerontol A Biol Sci Med Sci 2003; 58(6): 555-60.

[17] Beere PA, Russell SD, Morey MC, Kitzman DW, Higginbothm MB. Aerobic exercise training can Reverse Age related peripheral circulatory changes in healthy older men. Circulation 1999; 100(10): 1085-94.

[18] Singh MA, Ding W, Manfredi TJ, et al. Insulin-like growth factor I in skeletal muscle after weight-lifting exercise in frail elders. Am J Physiol 1999; 277(1 Pt 1): E135-43.

[19] Sullivan KJ, Brown DA, Klassen T, Mulroy S, Ge T, Azen SP, Winstein CJ. Effects of specific locomotor and strength training in adults who where ambulatory after stroke: results of the STEPS randomized clinical trial. Phys Ther 2007; 87(12):1580-602.

[20] Sluijs EM, Kok GJ, van der Zee J. Correlates of exercise compliance in physical therapy. Phys Ther 1993; 73(11): 771-86.

[21] Sluijs EM, Kuijper EB. Problems patients encounter in educating patients [in Dutch]. Nederlands Tijdschrift voor. Fysiotherapie 1990; 100:128-32.

[22] Brach JS, Simonsick EM, Kritchevsky S, Yaffe K, Newman AB. The association between physical function and lifestyle activity and exercise in the health, aging and body composition study. J Am Geriatr Soc 2004; 52(4): 502-9.

(C) Bichay et al.; Licensee Bentham Open.

This is an open access article licensed under the terms of the Creative Commons Attribution Non-Commercial License (http://creativecommons.org/licenses/by-nc/3.0/) which permits unrestricted, non-commercial use, distribution and reproduction in any medium, provided the work is properly cited. 